\title{
Subject Index Volume 6 (1996/1997)
}

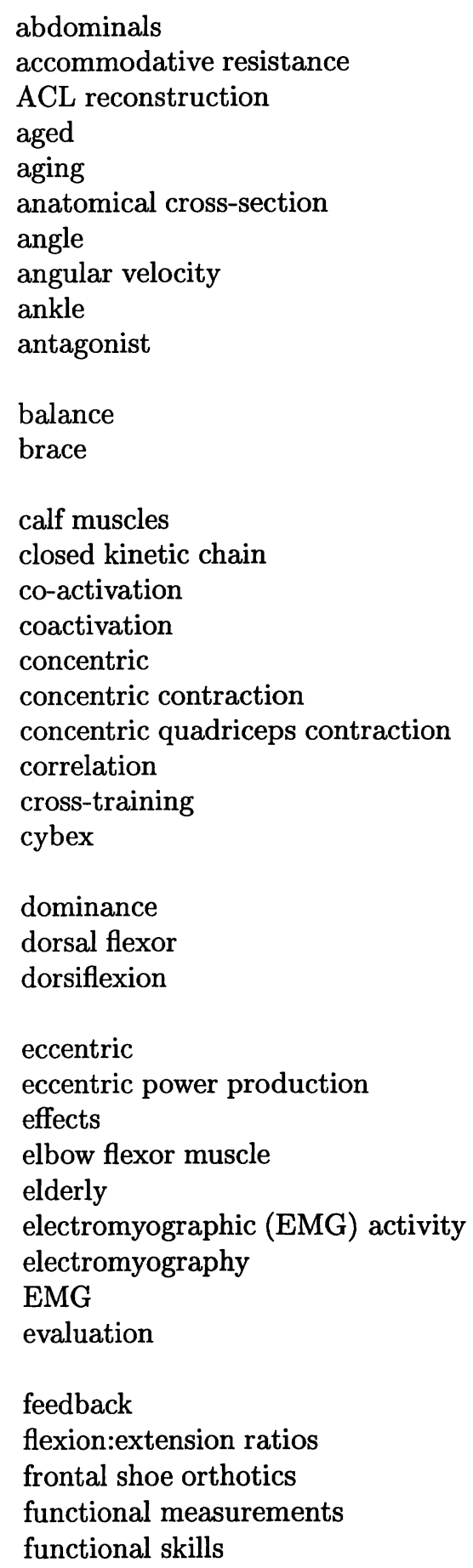

\begin{tabular}{|c|c|c|}
\hline 187 & functional tasks & 203 \\
\hline 197 & functional tests & 1,7 \\
\hline \multicolumn{3}{|l|}{$1,7,109$} \\
\hline 163 & gastrocnemius & 71 \\
\hline 125 & gravity correction & 89 \\
\hline \multicolumn{3}{|c|}{ 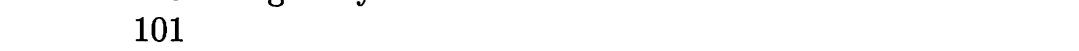 } \\
\hline 215,223 & hamstrings & 157 \\
\hline \multicolumn{3}{|l|}{215,223} \\
\hline 153 & increase hamstring flexibility & 181 \\
\hline \multirow[t]{2}{*}{21} & intraclass correlation coefficient (IC & 117 \\
\hline & isokinetic moment & 21 \\
\hline 125 & isokinetic muscle performance & 125 \\
\hline \multirow[t]{2}{*}{133} & isokinetic testing & 15,145 \\
\hline & isokinetics $\quad 51,57,65,79,89$, & 117,133 \\
\hline 163 & & $, 215,223$ \\
\hline 7 & isometric contractions & 71,157 \\
\hline 21 & isotonic & 41 \\
\hline \multicolumn{3}{|l|}{79} \\
\hline $21,101,175$ & joint displacement & 215,223 \\
\hline 197 & junior high school football players & 45 \\
\hline 145 & junior tennis & 15 \\
\hline \multicolumn{3}{|l|}{203} \\
\hline 101 & knee & 79,153 \\
\hline \multirow[t]{2}{*}{235} & knee flexion & 57 \\
\hline & knee kinematics & 145 \\
\hline \multicolumn{3}{|l|}{235} \\
\hline 235 & magnetic resonance imaging & 101 \\
\hline \multirow[t]{2}{*}{153} & major muscle groups & 33 \\
\hline & measurement error & 215,223 \\
\hline 21,175 & men & 163 \\
\hline 27 & muscle contraction & 41 \\
\hline 27,181 & muscle function & 65 \\
\hline 27 & muscle power & 41 \\
\hline 125 & muscle strength & 57,209 \\
\hline 71,157 & muscular force & 197 \\
\hline 21,133 & muscular power & 197 \\
\hline \multicolumn{3}{|l|}{79} \\
\hline \multirow[t]{2}{*}{51} & one-legged hop test & 1 \\
\hline & open kenitec chain & 7 \\
\hline \multicolumn{3}{|l|}{209} \\
\hline 33 & passive stiffness & 163 \\
\hline 45 & patella & 133 \\
\hline 45 & peak torque & 175,181 \\
\hline 203 & plantar flexor & 235 \\
\hline
\end{tabular}


plantarflexion

plyometric

plyometric training

position

postpartum

previous contraction condition

protocol

reliability

review

sagittal plane translation

sex

shoulder

single versus multiple joint testing

SLR

squat exercise
Subject Index/Isokinetics and Exercise Science 6 (1997) 247-248

153 strength

51,125

strength measurements 203

45 strength profile 33

235 submaximal effort 139

187

27 test position 57

139 time to peak torque 175 torque $\quad 153,157,215,223$

41, 117 trunk flexion/extension ratios $\quad 89$

117 trunk flexion/extension strength 15

235 validity 139

51 velocity 65

$\begin{array}{lll}109 & & \\ 181 & \text { work } & 181\end{array}$ 